\title{
Bond strength analysis of repaired concrete based on polymerization of glycoluril formaldehyde
}

\author{
SKM. Pothinathan*,***,****, M. Muthukannan**, N. Selvapalam** and S. Christopher \\ Gnanaraj*
}

* Department of Civil Engineering, Kalasalingam Academy of Research and Education, Krishnankoil, Tamilnadu, India

** Department of Chemistry, Kalasalingam Academy of Research and Education, Krishnankoil, Tamilnadu, India

**** Corresponding Author: s.k.m.pothinathan@klu.ac.in

\author{
Submitted :04/05/2020 \\ Revised :07/08/2021 \\ Accepted : 16/08/2021
}

\begin{abstract}
Repairing old concrete includes the correct choice of material and methodology adopted, which may not affect the quality providing monolithic condition for old and new concrete. This study investigates two different parameters such as the impact as well as optimum usage of new polymer glycoluril formaldehyde as a bonding material. The second one is about to understand the surface preparation for increased bonding strength at the interfacial area of old and new concrete. Five different types of surface textures are used to estimate the bond strength such as plane, lined, waved, grid, and chipped. Glycoluril aids as a bonding material in both old and new concrete, and it is introduced at $0 \%, 1 \%, 2 \%, 3 \%$, and $4 \%$ into the cement mixture. When the surface preparation creates a rough surface, it helps in repairing the concrete with the help of polymerization of glycoluril formaldehyde, which promotes the enhancement of bond strength and slant shear. The bond strength of the specimens was measured by slant shear method in compression as well as tension for a period of 1 week and 2 and 4 weeks of new concrete. The results indicated that the highest bond strength was achieved in 3 percentage addition of glycoluril and grid patten substrate preparation.
\end{abstract}

Keywords: Bond Strength; Slant shear; Glycoluril formaldehyde; Shear stress; Repairing concrete.

\section{INTRODUCTION}

Concrete [1] is a flexible and self-adaptable construction material that is used worldwide. A block of concrete is mainly a mixture of fine and coarse aggregated particles blended with a cement fluid and left to harden as time passes by. Different types of binders are mixed with some hydraulic cement to form the concrete mixtures. The Portland cement concrete is formed by binding it together with calcium aluminate cement or with Portland cement. Polymer concrete is formed by using any one polymer as binding material. Nowadays, concrete can withstand any material owing to the bonding agent creating a firm and enduring hardened concrete exterior. Epoxy glue is mainly used as a bonding agent, which consists of two liquids, in which one acts as base and the other as a hardener by mixing at the time of application. The damage that occurs in the construction sites due to natural disasters, soil issues, construction faults, incorrect design, chemical, and mechanical changes overtime is unavoidable in most of the cases. Therefore, the concrete structures built should be regularly monitored closely for any damage to provide immediate 
service in case of renovation and repairing. Nowadays, people prefer repairing instead of reconstruction because it gives a timely solution. But the available repairing polymers in market were having demerits like the poor fire and thermal resisting property of epoxy along with a diminishing strength property in the latex [Pothi et al., 2021].

This work aims to involve glycoluril as base material and formaldehyde as curing agent to repair the damaged places in the construction sites instead of replacing them as a whole. The solution offered is mainly a cost-effective and less time-consuming process than renovating the entire damaged structure. Glycoluril formaldehyde (GF) resin is formed by a cross-linkable aminoplast that occurs when glycoluril and formaldehyde react together. The lower crosslink density that exists in GF when cured with functional polymers helps give the concrete structure improved rigidity and toughness. GF sticks together well with the underlying metallic substrate, releases less formaldehyde during the curing process, and is resistant to ultraviolet rays, which makes it more appropriate when used for the exterior surface of the buildings and provides a longer life. The significant factor that corresponds to reducing the concrete repair is the bonding strength that exists between the underlying and overlying concrete (Climaco et al., 2001). Surface preparation is a significant aspect that creates an interface between the old and new concrete (Mirmoghtadaei et al., 2015). The bond strength is mainly improved by factors such as exterior roughness, minor cracks, compaction, and curing. The efficiency of GF in repairing the cracks that occur in the underlying substrate is measured by using two techniques such as slant shear and pull-off method (Júlio et al., 2004, Mirmoghtadaei et al., 2015). The pull of method is utilized to estimate a materials bond strength and minimize the effect of stress concentration (P. Bocca., 1984). The slant shear is employed to measure the bond strength between the old and new concrete (Diab et al., 2017) when the material is subjected to failure. The pull-off method shall be executed both in situ and in the laboratory, and then, the slant shear method is to be conducted only in the laboratory. This research work adds a new concrete layer to an existing concrete layer by using glycoluril as a bonding medium to the cement layer. The surface is equipped with $1 \mathrm{~cm}$ cement paste along with $1-4 \%$ glycoluril. To add a new concrete layer to an already existing layer, the surface should be coarsened first to help the binding materials stick together. The slant shear test is utilized here to estimate the bond strength of this work. The slant shear test utilizes a cylindrical slab cut into two halves. Every part has a vertical diagonal of $30^{\circ}$. The bond strength of the concrete mainly depends on two main factors:

- The chemical reaction between the repair materials and the underlying surface.

- The concrete surface roughness.

The concrete surface roughness is the most critical parameter that aids in binding the underlying and overlying concrete. A perfect bonding between new and old concrete promotes a sound structure with appropriate binding agent [Pothi et al., 2020]. The concrete should always be built in a manner to increase the shear strength. When the compression strength of the new concrete is higher than the old concrete, it leads to a monolithic rupture. Bond strength also decreases with the period of both the new as well as old concrete added. The only time the bond strength increases is when the new and old concrete mixture has the same mix and the same period (Ji-Tai et al., 2010).

This research article aims to introduce a new polymer-based binding agent named glycoluril formaldehyde (GF). A patent was claimed by Arthur H. Gerber (1986), containing glycoluril in concrete, and no further observable examination is conducted for such kind of polymer. In this study, the adhesion property of old and new concrete using glycoluril-cement paste as binding material with different dosage levels $(0 \%, 1 \%, 2 \%, 3 \%$, and $4 \%)$ to achieve optimum bonding strength was examined with various types of surface texture (plane, lined, waved, grid, and chipped). The significant factor in improving the bond strength is to use an appropriately prepared surface, which enhances the shear strength of the concrete. Bond stress was evaluated by the slant stress. 


\section{LITERATURE REVIEW}

In the past few years, many researchers have proposed various methods to strengthen the concrete base. In [6], Mohammadi et al. (2014) discussed the utilization of different chemical elements like silica fume, two kinds of metakaolin, plain cement slurry and bonding slurry [BS], that improved the concrete strength. Metakaolin phase B progresses the bond strength of the concrete. Among them, BS is not suitable to repair the concrete with low performance. Hawa A et al. (2013) [7] used geopolymer mortar such as metakaolin assorted with parawood ash (PWA) and oil palm ash (OPA). However, metakaolin based PWA and OPA contribute less to repairing the concrete. Hence, the research developed new eco-friendly materials for strengthening the concrete repair. The metakaolin geopolymer mortars and carbon fiber reinforced polymers (CFRP) were utilized for improving the bond strength of concrete as mentioned in Vasconcelos et al. 2011 [8]. Here, the bond strength among CFRP and geopolymer mortars is low, and this is not an expected outcome. Moreover, CFRP was not perfect for this level of retrofitting, and geopolymer mortars were costlier when compared to Portland cement.

Kramar S et al. (2016) [9] introduced alkali material for concrete repair. This concrete repair mainly occurs due to building faults, or any other natural disaster caused by the building. Various fly ashes, ground granulated blast furnace slag, and metakaolin are mixed with alkali materials for the concrete repair. Laskar and Talukdar (2017) [10] used an ultra slag based geopolymer to renovate the concrete. However, the performance was low in workability and strength parameter. The sand concrete is utilized as a repair component for concrete in Gadri and Guettala. (2017) [11]. However, the quality and strength of concrete became low. Tayeh et al. (2013) [12] proposed a method called interfacial bond among earlier concrete substrate and ultra-high-performance fiber concrete repair compound (UHPFC). Here, a various-testing method is employed to estimate the strength of concrete, that is, slant shear testing, scanning electron microscopy, and rapid chloride permeability test. Moreover, durability and workability became low in this method. Pacheco et al. (2013) [13] had widely described alkali-activated metakaolin based mortars for the repair of concrete; here, mechanical strength and workability had low.

Self-consolidated concrete (Diab et al., 2017) is used to repair the damaged construction sites by using latex at ten times that of cement rate. The major criteria when repairing the old concrete are illustrated here. The underlying concrete should be strengthened enough by using large grooves to enhance the bonding capacity between the two layers of concrete. Whenever applying new concrete, the mixture should be like that of the old concrete coarseness and aggregate type because the old concrete roughness has a significant effect on inducing bonding. The new concrete mixture compressive strength and bond strength are affected if the strength value mainly differs from the old concrete layer strength. Another factor that determines a bond strength is the test methods (Momayez et al., 2005) used. Some of the tests employed for evaluating the bond strength are pull-off, slant-shear, splitting prism, and bi-surface shear test. Momayez et al. (2005) used a bi-surface shear test to evaluate the weak link that reduces the bonding effect by performing the shear stress test at the interface itself. The results demonstrated that silica fume contact and rough surfaces are the two factors that increase the bond strength. Failure (P. Dybel et al., 2017) mainly occurs in the concrete when bonding the old and new layers by adding a thin layer of an overlay to the existing concrete.

Repairing the old concrete is an interesting topic. It provides a solution to the construction industry, which reduces the cost of demolition and reconstruction. Market available repairing materials aid solutions to the above problems. However, they are having a few faults within, like low performance of Metakaolin, less durability and workability property of UHPFC, diminished mechanical strength, and acid resistance properties of latex. This is an ideal opportunity to consider the new polymer to outdo the shortcomings of available repairing agents. 


\section{EXPERIMENTAL INVESTIGATION}

\section{Materials Used in this Study}

This research is comprised of materials such as Portland Cement, Fine aggregates, GF gel, HCL, M30 grade concrete, and water throughout the repairing process. The fine aggregate used is Zone-I natural river sand, which offers only a few void spaces during bonding and reduces the usage of Portland cement in high quantity. The river sand possesses the following physical specifications: Specific Gravity-2.70, Water retention capacity-2.90, and fitness modulus of 3.36. The cement used here is ordinary Portland cement of grade 43 (IS- 8112), which helps achieve the average compressive strength after 28 days of curing. Glyoxal, Benzil, and Urea are combined to form glycoluril. The glycoluril is synthesized (J.-T. Li et al., 2010) under ultrasound irradiation using potassium hydroxide as a catalyst. Formaldehyde is a material that is formed after the oxidization of methanol. Around $37 \%$ of store brought aqueous formaldehyde for the polymerization process, which is a combination of formaldehyde gas in the air. The GF gel is obtained by fusing two materials, that is, glycoluril and formaldehyde together by a polymerization process. Thus, the M30 grade concrete is created.

\section{Measuring the Roughness of the underlying Concrete Surface}

To fuse the old and new concrete, the roughness serves as an important factor. To recognize the bond strength of the old concrete before repairing, its surface should be prepared in a rough manner to help the new concrete stick together. The techniques used to create roughness were lined, grid, waved, and chipped by steel knife.

\section{Measuring the Underlying Concrete's Roughness Using the Slant Shear Test}

The techniques portrayed above to create roughness are checked with the slant shear method. The specimens are cured at a time interval ranging from 1 week and 2 and 4 weeks. The roughness is considered as an important parameter for conducting the slant shear test. The slant shear test value varies based on the roughness of the underlying surface. If the roughness is high, the slant shear test value also increases. Higher slant shear value indicates a greater bond strength present in between the old and new concrete surfaces. To create a good bond strength, the roughening process should be done deep in the old concrete by using any apparatus. This process helps in the efficient repairing of difficult building structures and historical monuments.

\section{Effect of Adding GF-Gel Paste To The Underlying Concrete Measured by Slant Shear Test}

The effect of using GF-gel paste to the underlying concrete to determine the slant shear bond test is reviewed here. GF improves the flexibility and toughness of the underlying concrete. During the curing process, it releases less amount of formaldehyde and provides better adhesion and UV resistant. From these properties, it is clear that the GF gel paste simultaneously increases the bond strength and provides an increased slant shear test result.

\section{EXPERIMENTAL PROCEDURE}

\section{Mixture Proportion}

To obtain the test results, three sets of cylindrical samples were casted and tested. For the first half-cylinder, old concrete samples are prepared as per ASTM C882, and interface roughness lines, grid, waves, and chipped were created using steel knife in the plastic stage. Then, the specimens are cast, and water cured for 28 days. Afterwards, 
the layer above the half-cylinder around $1 \mathrm{~cm}$ thick cement glue is mixed with the addition of $1 \%$ to $4 \%$ glycoluril. Following that, the glycoluril mix is applied on the diagonal surface, and new concrete can be developed.

A concrete mixture is a combination of cement, sand, and concrete aggregate in an appropriate ratio. The strength of concrete depends upon the proportion of mixture in which the binding materials are combined. The specimens were casted for M30 grade concrete. The cement: sand: aggregate ratio in M30 grade cement is 1:0.75:1.5. The sand is applied to half the aggregate volume. Water is added at an approximate level to increase the workability of the concrete. Too much water reduces the strength of the concrete, so here water is added as per the M30 grade concrete standards. The sample specimen created using the mixture proportion described above is illustrated in figure 1.

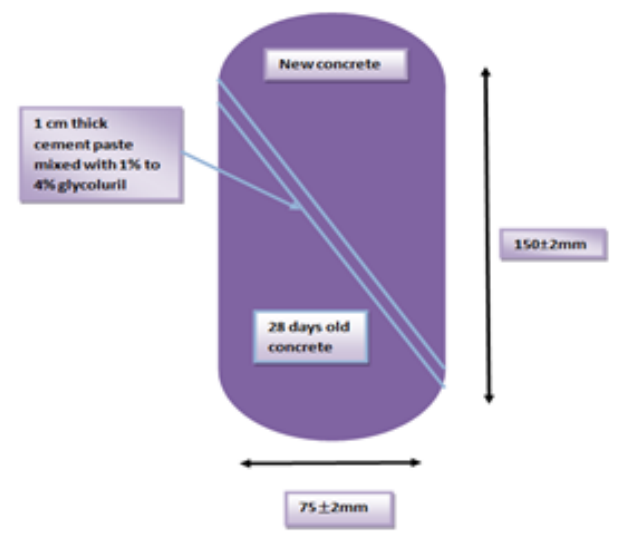

Figure 3. Sample preparation of Specimen created with approximate Mixture Proportion.

Table 1. Concrete mix portion.

\begin{tabular}{|c|c|}
\hline Materials & Existing Concrete \\
\hline Coarse aggregate & 850 \\
\hline Water & 185 \\
\hline Slump & 56 \\
\hline Glycoluril & - \\
\hline Cement & 300 \\
\hline River sand & 1105 \\
\hline
\end{tabular}

\section{Bond Strength}

The strength of the bond for the repaired concrete was examined during the results evaluated from the analysis of tensile strength as well as the compressive strength. The value equivalent to three tests was examined. The test results of the prepared samples (Pattnaik et al., 2007) were achieved by compressive strength, tensile strength, and 
bond strength, while the strength of the bond is considered as the maximum load for further analysis. The specimen of the cylinder was tested at 1 week, 2 weeks, and 4 weeks from the day of casting the entire specimen as well as with polymerized monomer that is aimed to enhance the strength of the concrete composite.

\section{Compressive Strength}

The compressive testing machine is used to evaluate the compressive strength of the specimens. The specimen is placed at the center of the pressure plate in the machine. Gradually, the specimen is loaded at the rate of $140 \mathrm{Kg} / \mathrm{cm} 2 /$ Minute $(68.5 \mathrm{kN} / \mathrm{sec})$ till failure as per IS 516.

The subsequent process of preparation on substrate concrete is submitted for studying the effect of surface preparation procedures based on the bond strength of overlay on substrate concrete.

a) Plane: after the concrete substrates are extracted from the mold, no further action is involved on sample surfaces.

b) Lines and Waves: to remove cement, metal knife is used to disclose them from an outer surface of specimen. This obtains a mean depth of $2-3 \mathrm{~mm}$, and the total length of lines was $133 \mathrm{~cm}$ approx., and the total length of wave pattern was $136 \mathrm{~cm}$ approximately (Fig. $2 \mathrm{~b}$ and c).

c) Grids: grooves were developed in series along the horizontal as well as vertical portion on the diagonal substrate surface. It has a depth of 2-3 mm as well as a width of $15 \pm 1 \mathrm{~mm}$, and a gap of $10 \pm 1 \mathrm{~mm}$ is created between each other with a total length of $130 \mathrm{~cm}$ approx. (Fig. 2a).

d) Chipped: chipped patterns are formed on the plane with a1 cm diameter metal rod at a mean depth of 3 $\pm 0.5 \mathrm{~mm}$ by applying pressure on the interfacial surfaces. Around $25 \mathrm{nos} \pm 1$ of chips are created on the substrate surface (Fig. 2d).

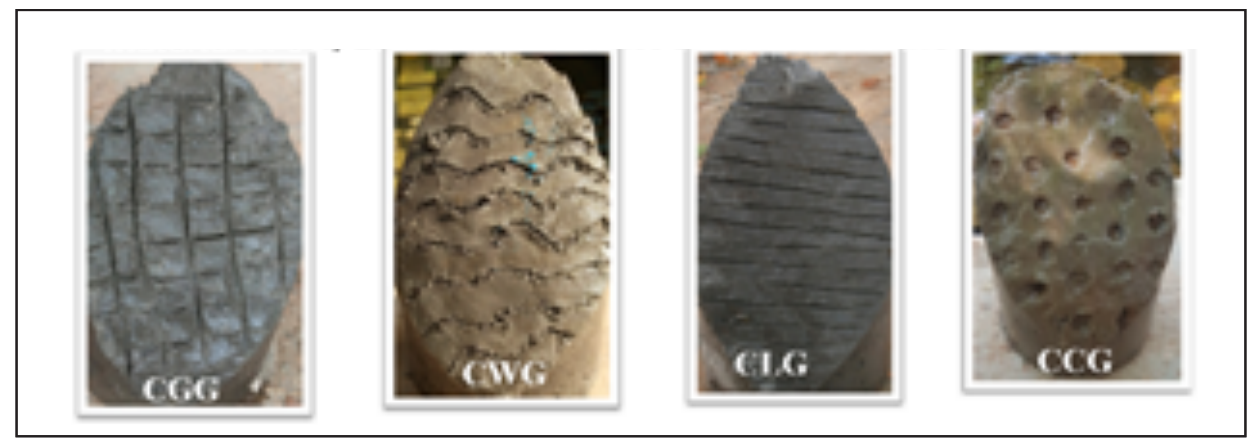

Figure 2. Surface preparation. a) Grid; b) waves; c) lines; d) chipped.

After the surface is roughened using specific tools like metal knife and rod, it is thoroughly cleaned and immersed in water for 28 days for curing process.

The full-cylindrical specimen is formed when the repair concrete is applied on the semicylindrical substrate with a diameter of $75 \pm 2 \mathrm{~mm}$ as well as $150 \pm 4 \mathrm{~mm}$ height. The full cylinders are extracted from the mold after 24 hours and cured in water. The slant shear test is loaded with the specimens at the ages of 1 week, 2 weeks, and 4 weeks. The curing time of full cylindrical samples in water is a maximum of one month. The full samples thus developed such as CPG, CLG, CWG, CGG, and CCG are noted in table 2 for the surface preparation methods. 
Table 2. Categorization of Specimens.

\begin{tabular}{|c|c|}
\hline Methods for Surface Preparation & Code of the specimen \\
\hline Plane & CPG \\
\hline Lined & CLG \\
\hline Waved & CWG \\
\hline Grid & CGG \\
\hline Chipped & CCG \\
\hline
\end{tabular}

\section{RESULTS AND DISCUSSION}

\section{Failure modes}

The results denoted in Table 3 show the failure modes that are classified into four groups:

- The interface of the substrate, as well as overlay concrete, failure occurs.

- Through the interface, the failure occurs with the occurrence of micro-cracks in the concrete substrate.

- Through the interface, the failure occurs suddenly after the formation of micro-cracks in the overlay concrete and due to debonding in the concrete substrate.

- Through the interface of overlay concrete as well as debonding, failure occurs.

Table 3. Specimens failure modes.

\begin{tabular}{|c|c|c|c|c|c|}
\hline \multirow{4}{*}{ Age of Specimen } & CPG & CLG & CWG & CGG & CCG \\
\hline \multirow{3}{*}{ First week } & iv & iv & iv & iii & iv \\
\cline { 2 - 7 } & iv & iv & iv & iii & iv \\
\cline { 2 - 7 } & iv & iv & iv & iii & iv \\
\hline \multirow{3}{*}{ Second week } & iv & iii & iii & i & ii \\
\cline { 2 - 7 } & iv & iii & iii & i & ii \\
\cline { 2 - 7 } & iv & iii & iii & i & ii \\
\hline \multirow{2}{*}{ Fourth week } & iv & iii & ii & i & ii \\
\cline { 2 - 6 } & iv & iii & ii & i & ii \\
\cline { 2 - 6 } & iv & iii & ii & i & ii \\
\hline
\end{tabular}


The notations used in the above table are described in section 4. The figures explain the bond strength with respect to compression and tension of control specimen, line, wave, grid, and chipped specimens, which consist of different percentages of glycoluril formaldehyde. The advancement of stress at interface results in diminished bond strength of the repaired specimens. This may be of stress development due to differential shrinkage in concrete interface of old and new concrete. Grid pattern showcased a 30\% increase in bond strength for a time period of 4th week, which performs well in controlling the interface differential shrinkage. Plane and lined patterns tend to show a lower bond strength when compared to other patterns.

\section{Compression Strength}

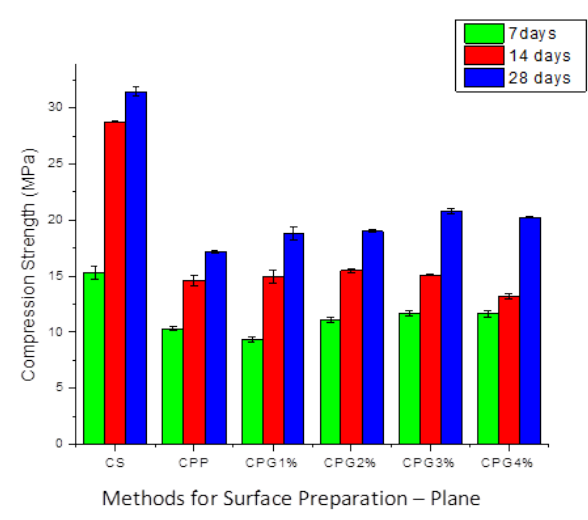

Figure 3. Bond Strength in compression of specimens in that overlay concrete contains plane pattern in interface.

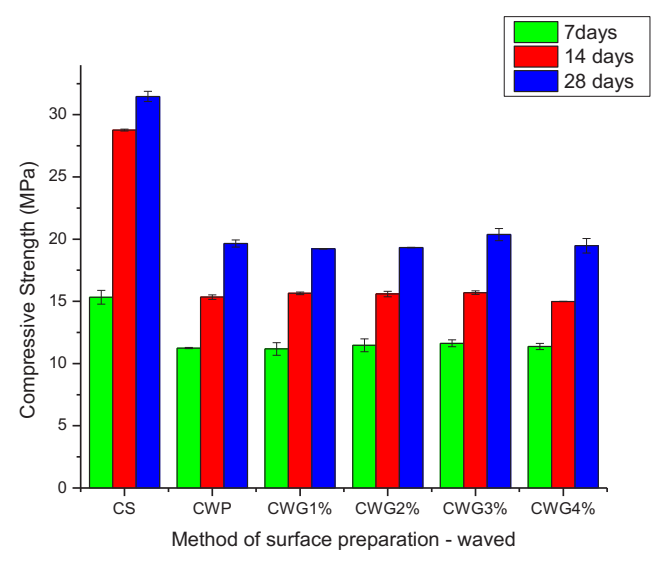

Figure 5. Bond Strength in compression of specimens in that overlay concrete contains waved pattern in interface.

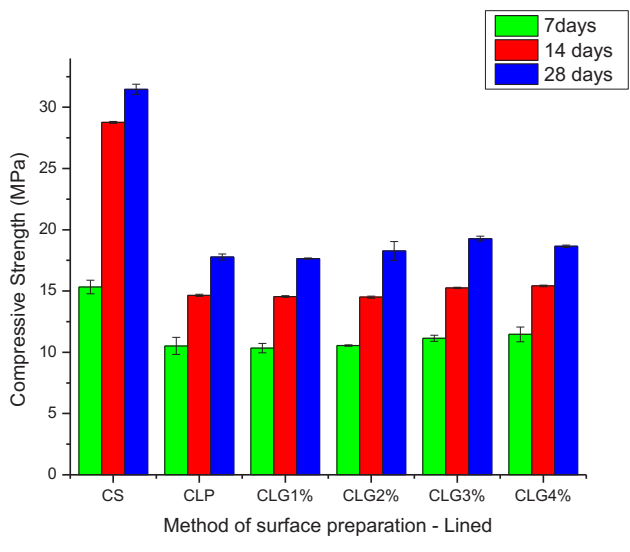

Figure 4. Bond Strength in compression of specimens in that overlay concrete contains lined pattern in interface.

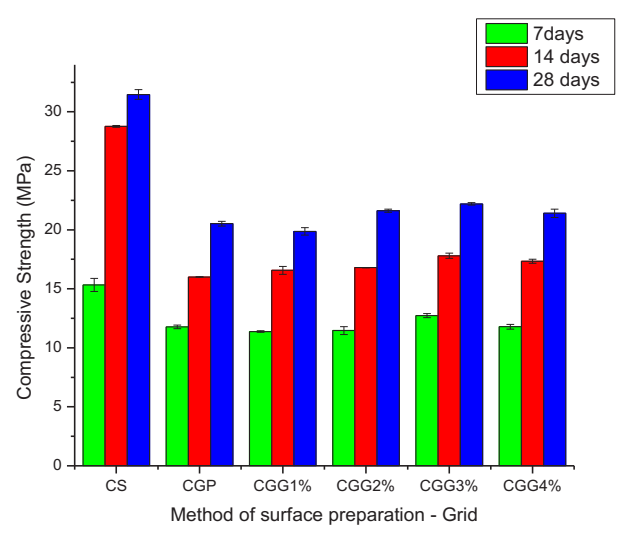

Figure 6. Bond Strength in compression of specimens in that overlay concrete contains grid pattern in interface. 


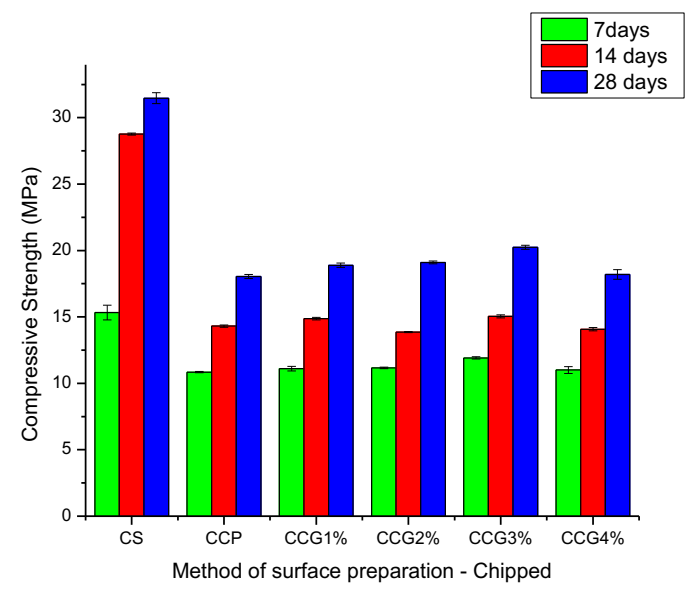

Figure 7. Bond Strength in compression of specimens in that overlay concrete contains chipped pattern in interface.

The figures depict the bond strength of plane, lined, waved, grid, and chipped specimens, which consist of $0 \%$, $1 \%, 2 \%, 3 \%, 4 \%$, and $5 \%$ glycoluril formaldehyde. The compressive strength is determined at 35 days, 42 days, and 56 days after the casting of half cylinder (considered as old concrete) as well as at 7 days, 14 days, and 28 days for new concrete. Compared with the full cylinder, the compression strength of slant specimen is minimum since the applied compressive force on the slant surface may act as principle tensile force. Due to this tensile force, the slant specimens do not contribute to the full cylinder.

Most of the cylinder failed with the slant surface, but the surface roughness of the specimen improved the strength property. The result shows that the addition of glycoluril as bonding agent interface increased the strength compared with the cement paste. Due to the polymeric dispersion in the glycoluril, the compressive strength of the specimen with glycoluril is noted to increase. This polymeric dispersion paves the way for sealing the pores and increasing the bond strength. Early strength development is also observed while incorporating cement paste as interface bonding material. Particularly, $3 \%$ addition of glycoluril showed considerable rise in result. The surface roughness also plays a key role in the strength enhancement. In this study, five different surface textures are studied: plane, waved, lined, grid, and chipped surface. In this surface preparation, increasing the bond strength but comparing all textures, grid surface provides good result. Thus, $3 \%$ addition of glycoluril in the cement paste as a bonding agent with surface roughness in grid pattern is recommended in comparison with the other patterns. 


\section{Tensile Strength}

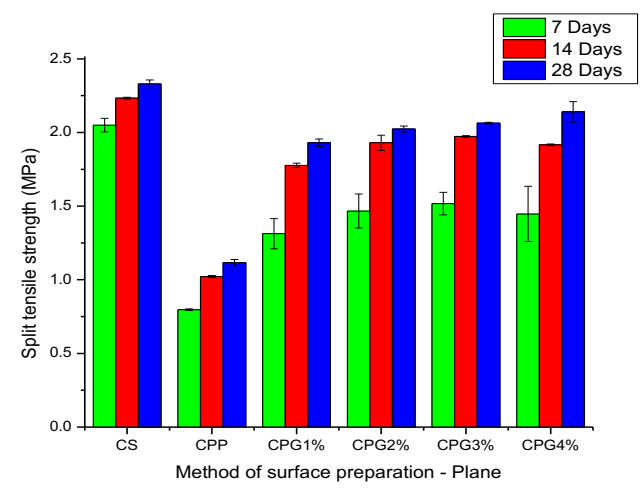

Figure 8. Bond Strength in tension of specimens in that overlay concrete contains plane pattern in interface.

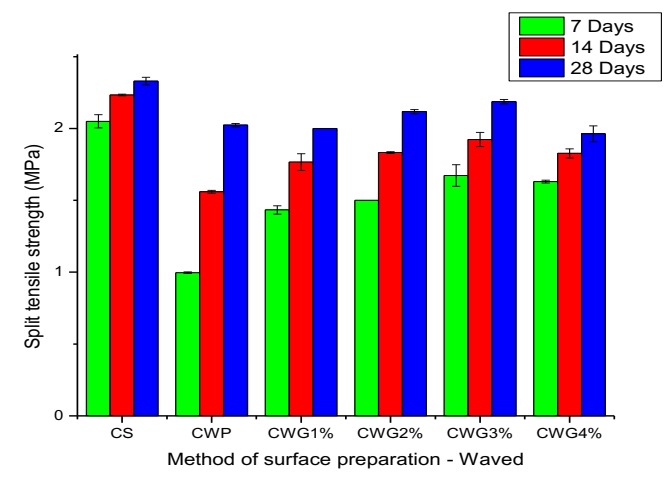

Figure 10. Bond Strength in tension of specimens in that overlay concrete contains waved pattern in interface.

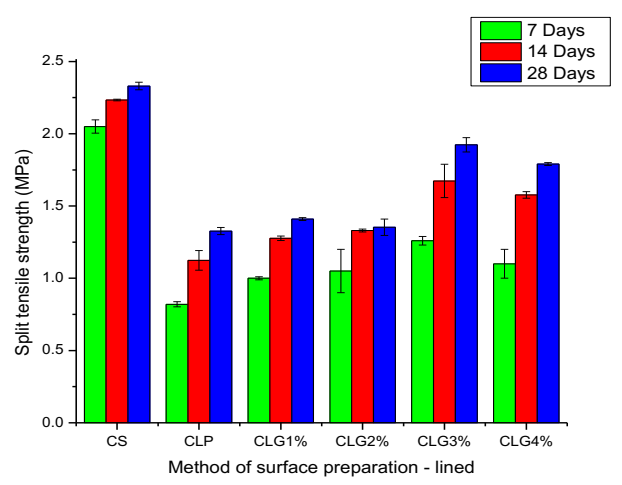

Figure 9. Bond Strength in tension of specimens in that overlay concrete contains lined pattern in interface.

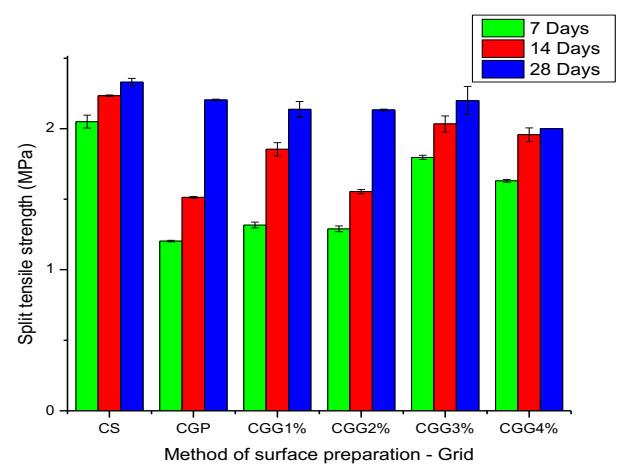

Figure 11. Bond Strength in tension of specimens in that overlay concrete contains grid pattern in interface.

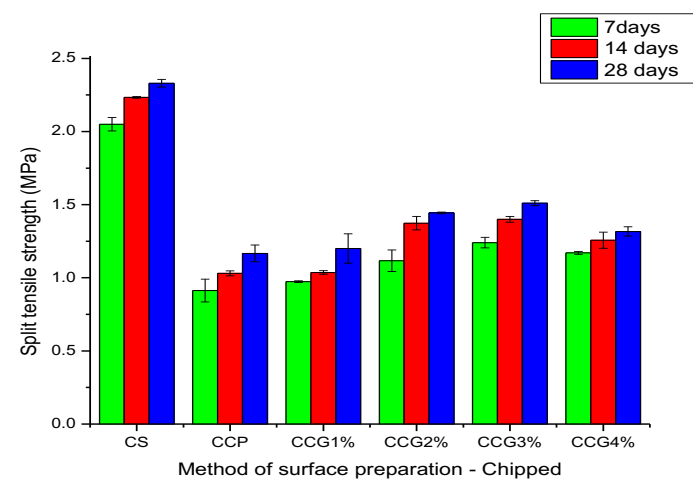

Figure 12. Bond Strength in tension of specimens in that overlay concrete contains chipped pattern in interface. 
The bond strength in tension is valuated with split tensile test. An average value corresponding to the 3 samples is tested for each type of interfacial concrete surface and presented in the above graphs [Fig. 8 to Fig. 12]. In general, the bond strength of the concrete interface is improved by increasing the glycoluril content in cement paste; when the same is extended up to $3 \%$, the bond strength is observed to decline. This is attributed to the excess polymer in cement paste that initiates hydration of the cement paste. This phenomenon is also observed by Ma et al. (2013) and Retno et al. (2014).

The surface roughness also enhanced the bond strength particularly in the specimens with grid pattern in the interfacial area. The assessment of the bond strength in tension zone proved that the increase of surface roughness and increased percentage of glycoluril content improved the bond strength. While comparing the surface roughness condition, we noticed that the grid pattern in concrete interface developed a significant rise in bond strength, whereas the line patterned specimens showcased poor bond strength. The results show that $3 \%$ addition of glycoluril with grid pattern exhibits a higher tensile strength among all other specimens for all the ages of concrete. Beyond the 3\% glycoluril addition, the tensile strength of the specimens similar to that of the compression strength is lowered.

\section{Water Absorption and Sorptivity Test}

Water absorption and sorptivity test were also conducted after four weeks of curing period. Initially, the specimens were oven-dried at $1050 \mathrm{C}$ for 24 hours, and constant weight of all the specimens was noted before testing. For sorptivity test, except the bottom, all the other three sides are coated with nonabsorbent resin. The results are clear that these two tests are not appropriate to find the properties of pores in the concrete specimens developed in this study since the weight of the specimens remains the same even after the absorption and capillary rise of water when compared with the control specimen. A small amount of polymer in the interfacial layer may not contribute to the density.

\section{Scanning Electron Microscope}

Since the water absorption and sorptivity test were found to be inappropriate to validate the pores and density parameters, scanning electron microscope (SEM) imaging test is conducted on the developed specimens. The microstructural SEM images (Figs. 13, 14) are presented for the 3\% addition of glycoluril with cement paste that is used in the interfacial zone. The images were obtained for two different dimensions such as $30 \mu \mathrm{m}$ and $3 \mu \mathrm{m}$ with magnitude of 1000x and 5000x, respectively. Addition of small amount of glycoluril in the binder resulted in the formation of denser microstructure with minimal air voids. No microcracks were detected in the SEM images owing to the presence of polymer that bonds well with hydrated cement enhancing the bonding cohesion and cement matrix strength. At higher magnification, few pores were noticed, whereas the major portion is observed to be closed packed owing to the presence of the polymer that adheres the cement hydrates. Chemical reaction between the NH group of reactive polymer and calcium hydroxide provides good bonding and better density for the concrete specimens. 


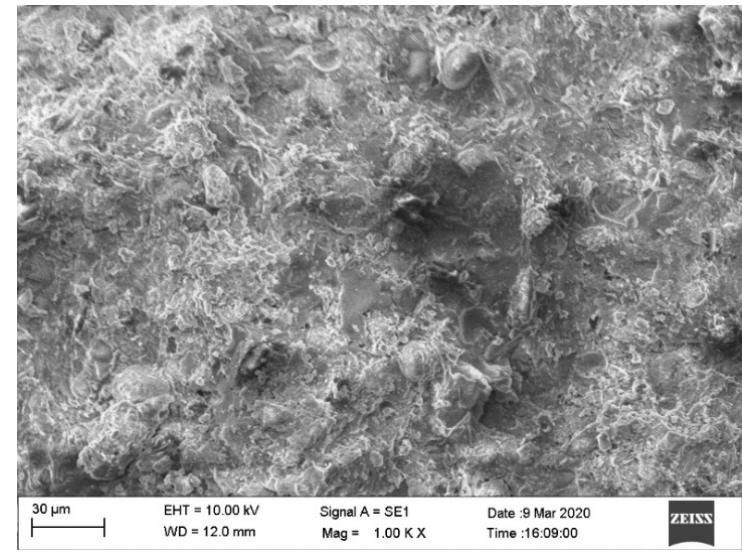

Figure 13. SEM image of $3 \%$ glycoluril addition at $30 \mu \mathrm{m}$.

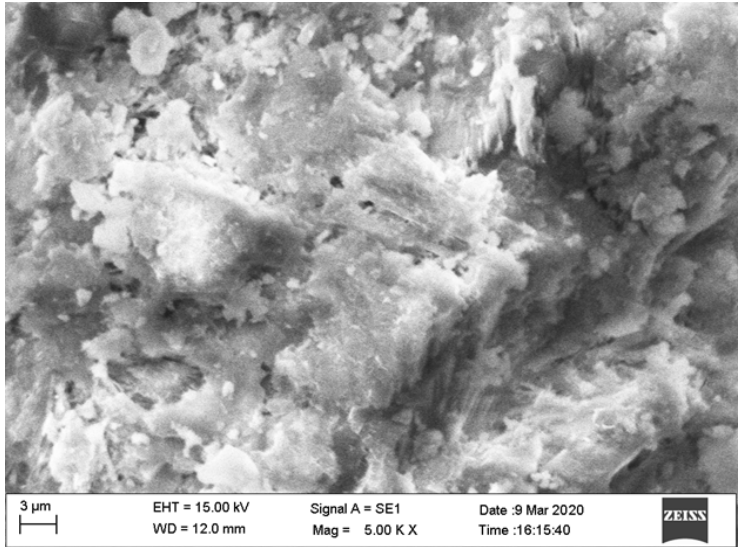

Figure 14. SEM image of 3\% glycoluril addition at $3 \mu \mathrm{m}$.

\section{SUMMARY AND CONCLUSION}

Based on the experimental analysis, the bond strength is evaluated at the interfacial zone, and the following conclusions were drawn:

1. The present paper introduces a novel approach for repairing old concrete using polymerization of glycoluril formaldehyde.

2. The major parameter considered for determining the bond strength between the old and new concrete together is the surface preparation and roughness, which also acts as an interfacial zone.

3. The slant shear test is conducted to measure the roughness of the underlying concrete surface. It is considered as one of the significant parameters in this study. The test is also carried out in a simplified approach. The slant shear strength is conducted to measure the bond strength of the repaired concrete in this proposed method, which tends to be slightly higher due to increased roughness.

4. A thick layer of the adhesive mixture is developed by combining cement paste and GF gel. This mixture is used in different proportions for about $1 \mathrm{~cm}$ thick between the two concrete layers to reconstruct the damaged old structures.

5. The overall performance is evaluated by measuring the compression strength and tensile strength of the concrete. From the results, it is evident that the strength of the new concrete is slightly lower than the old concrete, which prevents the monolithic rupture. But the $3 \%$ addition of glycoluril in the concrete interface provides considerable bond strength against the loading.

6. Five techniques, that is, plane, lined, waved, grid, and chipped patterns, are used in this paper to measure the bond strength between the underlying and overlying substrate. Among these concrete specimens, the grid pattern yields relatively higher performance in repairing the older concrete. The combination of $3 \%$ glycoluril formaldehyde with grid layer at interface resulted in improved resistance of the interfacial concrete surface failure and provided greater bond strength.

7. Hence, the proposed method is effective in rebuilding the old construction sites. 


\section{REFERENCES}

Susan Trolier-McKinstry, Robert E. Newnham. 2018. Cement and Concrete. Materials Engineering. Cambridge University Press. pp. 363-381.

J. C. T. S. Climaco and P. E. Regan. 2001. Evaluation of bond strength between old and new concrete in structural repairs. Magazine of Concrete Research, vol. 53, no. 6, pp. 377-390.

E. N. Júlio, F. A. Branco, and Silva Vítor D. 2004. Concrete-to-concrete bond strength. Influence of the roughness of the substrate surface. Construction and Building Materials, vol. 18, no. 9, pp. 675-681.

P. Bocca. 1984. The application of the pull-out test to high strength concrete estimation. Matériaux et Constructions, vol. 17, no. 3, pp. 211-216.

A. M. Diab, A. E. M. A. Elmoaty, and M. R. T. Eldin. 2017. Slant shear bond strength between self-compacting concrete and old concrete. Construction and Building Materials, vol. 130, pp. 73-82.

Mohammadi M, Moghtadaei RM, Samani NA. 2014. Influence of silica fume and metakaolin with two different types of interfacial adhesives on the bond strength of repaired concrete. Construction and Building Materials, vol.51, pp.141-150.

Hawa A, Tonnayopas D,Prachasaree W, Taneerananon P. 2013. Development and performance evaluation of very high early strength geopolymer for rapid road repair. Advances in Materials Science and Engineering.

Vasconcelos E, Fernandes S, De Aguiar JB, Pacheco-Torgal F. 2011. Concrete retrofitting using metakaolin geopolymer mortars and CFRP. Construction and Building Materials", vol.25, no.8, pp.3213-21.

Kramar S, Šajna A, Ducman V. 2016. Assessment of alkali-activated mortars based on different precursors with regard to their suitability for concrete repair. Construction and Building Materials, Vol.124: pp.937-944.

Laskar SM, Talukdar S. 2017. Preparation and tests for workability, compressive and bond strength of ultra-fine slag based geopolymer as concrete repairing agent. Construction and Building Materials. Vol. 15:154: 17690.

Gadri K, Guettala A. 2017. Evaluation of bond strength between sand concrete as new repair material and ordinary concrete substrate (The surface roughness effect). Construction and Building Materials. Vol. 30:157:1133-44.

Tayeh BA, Bakar BA, Johari MM. 2013. Characterization of the interfacial bond between the old concrete substrate and ultra-high-performance fibre concrete repair composite. Materials and structures. Vol $1: 46(5): 743-53$.

Pacheco-Torgal F, Moura D, Ding Y, Jalali S. 2011. Composition, strength and workability of alkali-activated metakaolin based mortars. Construction and Building Materials. Vol 1:25(9):3732-45.

Ji-Tai Li, Xiao-Ru Liu, Ming-Xuan Sun. 2010. Synthesis of glycoluril catalyzed by potassium hydroxide under ultrasound irradiation. Ultrasonics Sonochemistry, 17, 55-57.

A. M. Diab, A. E. M. A. Elmoaty, and M. R. T. Eldin. 2017. Slant shear bond strength between self-compacting concrete and old concrete. Construction and Building Materials, vol. 130, pp. 73-82.

A. Momayez, M. Ehsani, A. Ramezanianpour, and H. Rajaie. 2005. Comparison of methods for evaluating bond strength between concrete substrate and repair materials," Cement and Concrete Research, vol. 35, no. 4, pp. 748-757.

P. Dybel and D. Walach. 2017. Evaluation of the Development of Bond Strength between Two Concrete Layers. IOP Conference Series: Materials Science and Engineering, vol. 245, p. 032056. 
Daniel Wałach, Piotr Dybel, Joanna Sagan, Magdalena Gicala. 2019. Environmental performance of ordinary and new generation concrete structures-A comparative analysis", Environmental Science and Pollution Research, Vol.26, pp. 3980-3990.

P. M. Santos and E. N. Júlio.2013. A state-of-the-art review on roughness quantification methods for concrete surfaces," Construction and Building Materials, vol. 38, pp. 912-923.

Roselin Sobha Joseph Boopaphi, Ramachandran Dasnamoorthy, Manoj Kumaar Chandrasekaran, Vinita Vishwakarma. 2021. Study on polymeric coatings on fly ash concrete under seawater", Environmental Science and Pollution Research, Vol.28, pp. 9338-9345.

Harry Franklin Porter. 1910. The Preparation of Concrete-From Selection of Materials to Final Deposition", Journal Proceedings, Vol. 6, No.2, pp. 287-303.

Pattnaik, Rashmi Ranjan, and Prasada Rao Rangaraju. 2007. Analysis of compatibility between repair material and substrate concrete using simple beam with third point loading. Journal of Materials in Civil Engineering 19, no. 12: 1060-1069.

Sarmad Dashti Latif. 2021. Concrete compressive strength prediction modeling utilizing deep learning long short-term memory algorithm for a sustainable environment. Environmental Science and Pollution Research, Vol.74.

Vinita Vishwakarma, Sudha Uthaman, Ramachandran Dasnamoorthy, Viswanathan Kanagasabai. 2020. Investigation on surface sulfate attack of nanoparticle-modified fly ash concrete. Environmental Science and Pollution Research, Vol.27,pp. 41372-41380.

R. Mirmoghtadaei, M. Mohammadi, N. A. Samani, and S. Mousavi. 2015. The impact of surface preparation on the bond strength of repaired concrete by metakaolin containing concrete. Construction and Building Materials, vol. 80, pp. 76-83.

SKM. Pothinathan, M. Muthukannan, N. Selvapalam and S. Christopher Gnanaraj. 2020. Comparison of bond strength analysis on the interfacial layer of old and new concrete using latex, epoxy and glycoluril, IOP Conf. Series: Materials Science and Engineering 983012006.

H. Ma, and Z. Li. 2013. Microstructures and mechanical properties of polymer modified mortars under distinct mechanisms," Construct. Building Mater., vol. 47, pp. 579-87.

R. M. I. Retno Susilorinia, H. Hardjasaputrab, S. Tudjonoc, G. Hapsaria, R. Wahyu Sa, G. Hadikusumoa, and J. Suciptoa. 2014. The advantage of natural polymer modified mortar with seaweed: green construction material innovation for sustainable concrete," Proced. Eng., vol. 95, pp. 419-25.

SKM. Pothinathan, M. Muthukannan, N. Selvapalam and S. Christopher Gnanaraj. 2021. Investigation on strength properties of polymer modified concrete using glycoluril. International Review of Applied Sciences and Engineering, vol 12, pp. 278-284.

Arthur H. Gerber, Solon, Ohio. 1986. Additive for Hydraulic cement” US Patent Aug 19.

Hamid Gadouri, Khelifa Harichane and Mohamed Ghrici. 2019. Effect of interaction between calcium sulphate and mineral additives on shear strength parameters of clayey soils. Journal of Engg. Research, Vol.7, No. (2), pp. 66- 88.

Khaldoun N. Rahal. 2020. Shear Strains at Service Load Conditions in Cracked Reinforced Concrete Elements Subjected to Shear. Journal of Engg. Research, Vol. 8, No. (4), pp. 80-98. 